\title{
B40 Online Business Platform: E-Commerce and Life Cycle Model Considerations
}

\author{
Mohamad Aqib Haqmi Abas ${ }^{1}$, Ahmad Ihsan Mohd Yassin ${ }^{2}$, Nooritawati Md Tahir ${ }^{1}$, \\ Azlee Zabidi ${ }^{3}$, Megat Syahirul Amin Megat $\mathrm{Ali}^{2}$ \\ ${ }^{1}$ College of Engineering, Universiti Teknologi MARA, Shah Alam, Malaysia \\ ${ }^{2}$ Microwave Research Institute, Universiti Teknologi MARA, Shah Alam, Malaysia \\ ${ }^{3}$ College of Computing and Applied Sciences, Universiti Malaysia Pahang, Pekan, Malaysia
}

\begin{abstract}
A new online business platform is needed in Malaysia. The proposed system aims to provide B40 household income group with the necessary knowledge for increasing readiness in online business, and equip them with access to available financing, e-commerce, and logistic solutions. Prior to project commencement, a review is performed on e-commerce and development life cycle models. The adopted approach includes issues such as client engagement, development team, duration of project, requirement of prototype, and scale of deployment. In this case, a modified Rapid Application Development model is suitable for monitoring project progress and delivery.
\end{abstract}

Keywords - B40, business platform, e-commerce, life cycle model, Rapid Application Development.

\section{Introduction}

Poverty is a critical issue in Malaysia [1]. However, the internet has shown the potential as an enabling medium to assist B40 to alleviate their socio-economic issues [2].

Government initiatives such as the crowdsourcing website e-Rezeki, allows part-time micro-jobs search online with reduced entry barrier, but temporary jobs are not sustainable as a long-term solution [3].

DOI: 10.18421/TEM103-36

https://doi.org/10.18421/TEM103-36

Corresponding author: Megat Syahirul Amin Megat Ali, Microwave Research Institute, Universiti Teknologi MARA. Email: megatsyahirul@uitm.edu.my

Received: 07 June 2021.

Revised: 29 July 2021.

Accepted: 03 August 2021.

Published: 27 August 2021.

(c) BY-NC-ND (C) 2021 Megat Syahirul Amin Megat Ali et al; published by UIKTEN. This work is licensed under the Creative Commons Attribution-NonCommercial-NoDerivs 4.0 License.

The article is published with Open Access at www.temjournal.com
Nationwide lockdown due to COVID-19 pandemic further aggravated this issue and the B40 segment are among the most affected [4]. Thus far, online businesses appeared to be the most viable alternative for sustainable income with tremendous growth potential. Similar trend has been observed in various countries [5]. The model is being widely adopted as it allows the entrepreneurs to minimize contact with customers, and therefore, reduces the potential spread of pandemic [6]. Central to these, however, will be the support system provided by online platforms, as well as the accessibility of B40 to the internet infrastructure and target market.

The PENJANA MyAssist platform that was introduced by the government provides information for small industries. The system provides opportunities for successful business that covers aspects such as financing, trade, branding, technology, as well as business matching with government-linked companies and e-commerce platforms [7].

However, there are major concerns with the system whereby there is no clear indication on the effectiveness of the training for small and medium enterprises. It also appears that the system lacks personalization aspects, thereby imposing a steep learning curve on new and aspiring entrepreneurs. Furthermore, the system is targeted for existing business owners and not focused on improving B40 household income by supporting new enterprises [8]. Hence, a new platform that assimilates and interfaces various successful e-commerce, social networking, payment, logistics, training, and financing websites is proposed.

Recently, the Ministry of Higher Education, Malaysia has awarded a budget for the development of such platform through the Long-Term Research Grant Scheme. The project is comprised of a multidisciplinary research team from Universiti Kebangsaan Malaysia (UKM), Universiti Utara Malaysia (UUM), and Universiti Teknologi MARA (UiTM). Among the three public universities, the team from UiTM is central to the development of the 
platform. UKM and UUM are both integral to the project as the client while the B40 segment are recognized as stakeholders. With a very small team and limited timeframe, these mount a challenge on how to best deploy the platform that passes the specifications and user-acceptance test.

This study provides an overview of e-commerce in Malaysia, as well as development life cycle models that cover conventional and contemporary methods. The discussions cover the Waterfall, Agile, and Rapid Application Development (RAD) models. These lead to the considerations in tackling prior issues and which model suits best for efficient deployment of business platform. The system aims to provide B40 segment with the necessary technical knowledge and language command to effectively utilize e-commerce websites, increase readiness to conduct online business, and equip them with access to available financing, e-commerce, and logistic solutions.

\section{E-commerce}

The World Trade Organization (WTO) has defined e-commerce as "the sale or purchase of goods or services, conducted over computer networks by methods designed for the purpose of receiving or placing orders" [9]. E-commerce has emerged as a disruptive technology that can contribute to national economic growth [10]. These are caused by global accessibility power through internet connectivity, lower barrier of entry due to reduced business cost and manpower, simplified management [11], and decreased time constraint, as well as ubiquitous access through mobile technology [12].

These are also attributed to the ease of access [13], appeal of wider selection, lower prices, bargains, responsiveness, and ease of transaction [14]. Data mining and analysis of e-commerce data from small and medium enterprises allows them to evaluate product growth, performance, and competitiveness [15]. Initiatives around the world and Malaysia are now inclined towards e-commerce. According to ECommerce Foundation, the revenues have increased significantly from USD 1.2 billion in 2012, to USD 2.27 billion in 2015 . The growth is expected to continue in an upward trend [9].

Revenue for Asia-Pacific region has also increased from $31.3 \%$ in 2012 , to $46.5 \%$ in 2015 , with Malaysia, Indonesia and India expected to be top fastest growing markets within the next 5 to 10 years [16]. At Southeast Asian region, the ASEAN Economic Community Blueprint 2025 was initiated to establish fair competition and increase regional cooperation for supporting the growth of e-commerce [9]. Furthermore, several trade agreements have also been initiated at the 11th WTO Ministerial Conference to support e-commerce [16].

China has also taken the initiative to help its rural population establish e-commerce with backing from its formidable state-supported industries. This has resulted in significant success, particularly in revitalizing rural industries, solving employment, and tackling poverty [17]. Similar approach was also taken by Iran. The nation has launched e-commerce for its agriculture sector for reducing dependency on petroleum [10]. Realizing similar potential, Malaysia has also targeted 500,000 retailers and manufacturers to adopt e-commerce, with expectations that they can penetrate 87 million customers in the ASEAN by 2020.

\section{System Development Life Cycle}

Prior to any system development projects, the team will decide on the most suitable life cycle models for monitoring progress and ensures successful delivery. For developing a new B40 online business platform, the team initially reviews the Waterfall model. Despite its limitations, this life cycle model has been widely implemented since the 1970s [18] and is a benchmark for the contemporary Agile and RAD solutions.

\subsection{Waterfall Model}

A system undergoes a complete life cycle from concept exploration to its retirement. Within this time span, it goes through broad phases of life cycle which include the requirements, design, implementation, integration, and maintenance [18]. Fig. 1. shows the development life cycle for a Waterfall model.

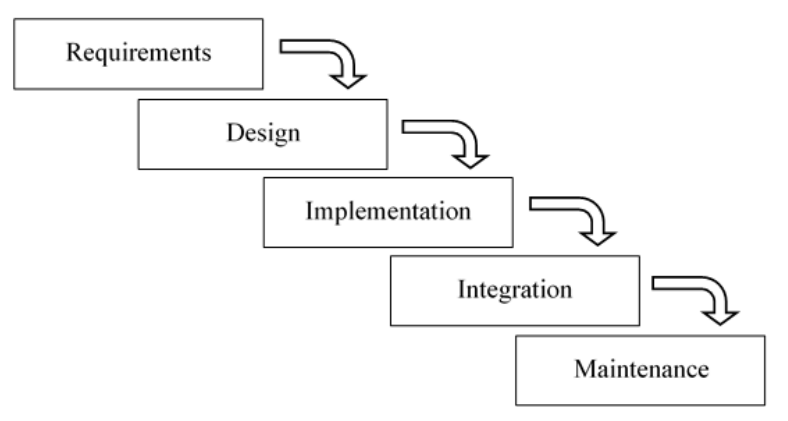

Figure 1. Waterfall model

In the requirements phase, concepts are explored and refined, and the requirements by clients are extracted. These are analyzed in the form of specifications document. Subsequently, the system undergoes the architectural and detailed design. Following this, the developed modules are coded and tested individually. In the integration phase, the different modules are combined and tested as a 
whole. Users will then perform the acceptance testing and ends when they are satisfied [19].

During maintenance, the system operates according to its intended specifications and is subject to corrective maintenance and updates. Any changes made during the updates only involve perfective and adaptive maintenance. Changes to system specifications are no longer viable. Once the system ceases to have any use by the organization, it will be retired. Hence, the Waterfall model can be summarized as a sequential development process that requires relatively less involvement from the clients [20].

\subsection{Agile Model}

The more efficient approach is proposed to solve the rigidity of Waterfall model. In the Agile model, systems are developed in an iterative life cycle. The model segregates the project phases into smaller iterations and allows monitoring of the outcomes by developers and the client. In the initial phase of development, scopes and requirements of the project are being discussed [20].

To avoid drawn-out timeline, the scope, duration, and number of iterations involved at each stage are clearly defined in advance. Each iteration, also known as sprint, is considered as a shorter timeframe in the model. The segregation of project into smaller parts minimizes the risk and reduces the delivery time. Each iteration involves a team working through a full system development life cycle that includes requirements, design, construction, testing, feedback, and deployment phases. The first four phases of Agile model follow similar process as the Waterfall model. However, at the feedback phase, developers will receive comments on any non-compliance with specifications and bugs. The information is then considered in the next iteration of requirements, design, construction, and testing. After iterations of improvement and having reached satisfaction by the clients, the system will be deployed as the final product [21]. Fig. 2. illustrates the development life cycle in an Agile model. The iterative cycle will only end and enters the deployment phase once the clients are satisfied.

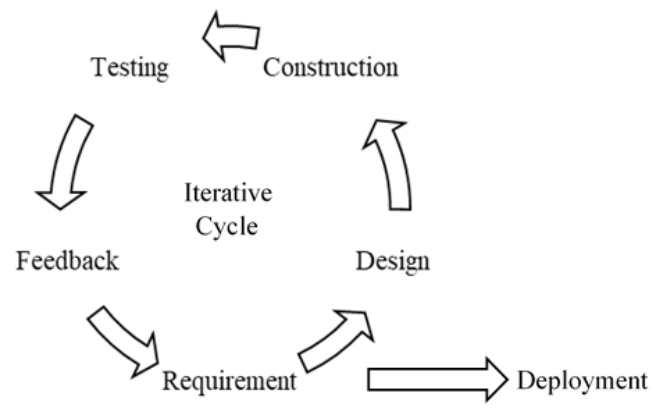

Figure 2. Agile model

\subsection{RAD model}

The model focuses on minimizing the planning stage and maximizing development of prototype. Through such approach, the RAD model allows developers and clients to accurately track progress and communicate on evolving issues and changes to the system. Generally, the model comprises of four main phases which include requirements planning, user design, rapid construction, and cutover [22].

The initial part of the model focuses on the objectives and expectations of the project, as well as current and potential issues that need to be addressed during the development. These are broken down into researching the current problem, defining, and finalizing the requirements with the clients' approval. During user design, the system is developed through various prototype iterations, and this is essentially the defining aspect of the model. At this phase, clients work together with the developers to ensure that the specifications are being achieved. Developer designs the prototype, and the clients will perform the testing [23].

After the clients are satisfied, the prototype from the design phase is converted into a working model. As majority of the problems have been dealt with earlier, the final model can be constructed much faster than the conventional approach. At this phase, rapid construction of program and applications, along with unit, integration and system testing can be performed. The cutover phase marks the implementation of system that includes data conversion, testing, changeover to new system, as well as user training [23]. The development life cycle for the RAD model is shown in Fig. 3.

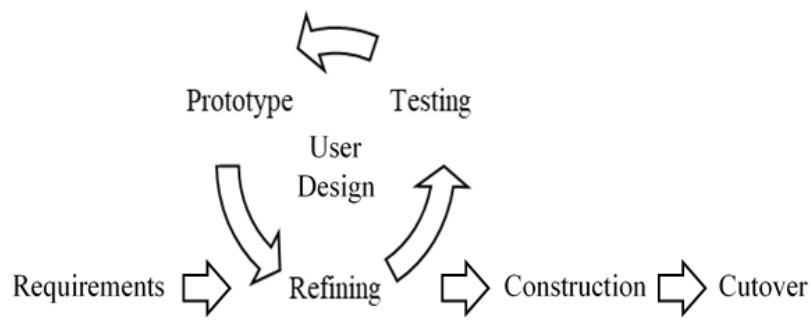

Figure 3. RAD model

\section{Discussion}

\subsection{Success Factors of E-commerce}

The Organization for Economic Co-Operation and Development has outlined four layers for success of e-commerce which include information flow, logistics, cash flow, and integration. These are the important criteria to be addressed by the emerging ecommerce economies [9]. Other critical factors also include reliable high-speed internet with good connectivity and rate of penetration [13], logistics 
infrastructure for delivery, storage, warehousing, tracking, customs and services, social and institutional systems [12], government support and initiatives [13], technology-savvy population with access to smartphones and computers [24], and optimal e-commerce applications to support the ecosystem [25].

Malaysia, together with Singapore and Thailand have steadily improved their network infrastructure. Internet is generally accessible, with 24.5 million users. According to 2016 statistics, the penetration rate is $76.6 \%$. Online purchases have also increased from $35.3 \%$ in 2015 , to $48.8 \%$ in 2016 [13]. The COVID-19 pandemic further pushes digitization of business and continues to apply pressure on the information technology infrastructure [26]. These show the potential for expansion of e-commerce in Malaysia [13].

Apart from the success factors, additional elements that include data analytics are also crucial to ensure the success of e-commerce. Current mainstream research focuses on areas such as sentiments, big data, and semantic analysis. Furthermore, there are also work on data management and extraction of useful information through data mining and distributed computing [27], security [28], and customized mobile applications [29]. Social media are also increasingly employed for marketing and selling goods [30].

Integration of cloud technology within the framework allows the information to be stored on the internet and thus, are accessible to a wide variety of devices. Among the advantages of cloud computing is scalability, ubiquity, reliability and cost-effective [14]. These are further enhanced through mobile devices that allow data transmissions without being connected through a physical link. The ubiquity of such technology enables data to be accessed from any location. These will have a significant potential as it is projected to generate a global revenue reaching USD 80 billion in 2020. With an increase in computing power and lower prices, the adoption of smartphones is expected to accelerate [31].

\subsection{Comparison of Life Cycle Models}

Each of the methods described previously has its own unique advantages and limitations. To better put into perspective, the comparison is made based on principle, project size, success measurement, adaptability, documentation, iteration cycles, and compliance of the development to the project requirements [32].

The conventional Waterfall model lacks flexibility and therefore, often result in minimal human error. The success of the system will be evaluated based on its conformity with the specifications. The major drawback of the model is that any changes to model later into the project is difficult to perform and it requires extensive documentation. The number of corrective cycles is limited and allocated during the integration phase. Furthermore, planning must be completed prior to project commencement [33].

Comparatively, the Agile model is very flexible and can easily adapt to the clients' needs and expectations. The approach is suitable for small- and large-scale projects. Success of the project is measured by functionality of the delivered system. The major advantage of the model is that it allows changes at any stage of the system development. The model also does not require extensive documentation and has many iteration cycles. However, this may tend to extend the project timeline and increase the overall cost. Minimal planning is required in the requirements phase as changes can be made later into the project [34].

Similarly with the Agile model, the RAD is client centric. However, the difference lies in that it focuses on prototypes before the system is being realized as a final product. Success of the project is also measured by functionality of the delivered system. Comparatively, the model allows changes to be made as it has many iteration cycles. As the changes and improvements are solely focused during the prototyping stage, the process therefore requires lesser time as compared to the Agile model. It does not require extensive documentation and minimal planning is required in the requirements phase as changes can be made during the user design phase [33].

\subsection{Development Constraints}

Several constraints are identified prior to commencement of the project. First, the start-up team at UiTM consist of a very small, but experienced team of developers. Therefore, a prototype-oriented approach that emphasizes on functionality is important. Second, the project not only have to consider feedbacks from clients, but also the B40 segment as stakeholders. Therefore, a two-tiered iterative loop involving the more experience clients, and those with less mastery of internet technology is required. Third, the platform is expected to be fully operational and deployed within a span of two years.

Following the review of development life cycle models, the selection is then based on the one that best matches the scopes and resources for developing the online business platform. The mapping in Table 1. shows that based on the project considerations, the RAD model is the most suitable. This lies largely on the fact that the system requires rapid prototyping, and the decision-making process also involves active participation of clients and stakeholders. 
Table 1. Mapping consideration to life cycle models

\begin{tabular}{|lccc||}
\hline \multicolumn{1}{|c|}{ Considerations } & \multicolumn{3}{c||}{ Life cycle model } \\
Client & Waterfall & Agile & RAD \\
engagement & & $\sqrt{ }$ & $\sqrt{ }$ \\
Small team & & & $\sqrt{ }$ \\
Initial prototype & $\sqrt{ }$ & & $\sqrt{ }$ \\
Large scale \\
project
\end{tabular}

\subsection{Considerations and Modified RAD model}

The e-commerce infrastructure and population readiness are well-established in Malaysia. However, in the development of new online business platforms for B40 segment, focus must be given to advanced analytics on the e-commerce data. Such features are currently not available on any existing platforms, and these are important for facilitating new entrepreneurs from the B40 segment to analyze market niche whilst functioning as a decision support mechanism. The overall objective of the platform is not only for these stakeholders to perform online business but also alleviate them into the M40 income group.

Despite the selection of the RAD model, the approach still needs to be modified for catering involvement of stakeholders in the development life cycle. Fig. 4. shows an additional loop outside of the client iteration, indicating the involvement of stakeholders. While collaborators from UKM and UUM tests and scrutinizes the development on frequent basis, the B40 segments will be involved during survey and training stages. Their feedbacks are crucial from the viewpoint of end users. Hence, the fully operational platform can only be deployed once having passed user-acceptance test by both clients and stakeholders.

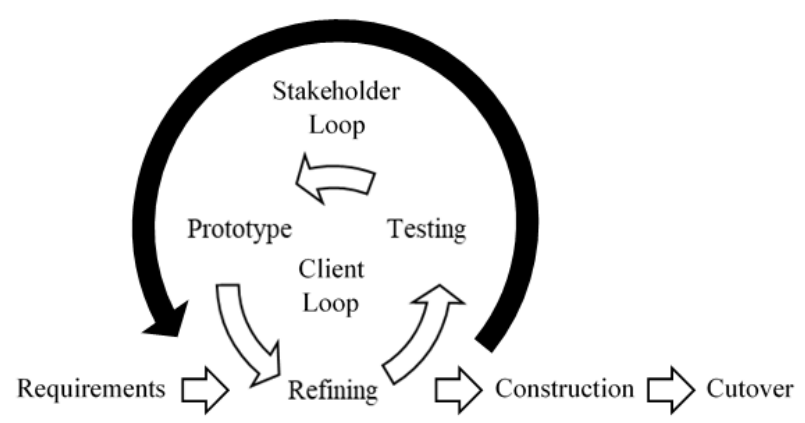

Figure 4. Modified RAD model

\section{Conclusion}

A new online business platform, dedicated for B40 segment is required. The project development which is funded by the Ministry of Higher Education, Malaysia will be delivered through a collaborative work between UKM, UUM and UiTM. This study has reviewed the success factors of e-commerce and life cycle models before embarking on the project. The information technology infrastructure and population readiness in Malaysia is well established. The new online business platform for the B40 segment will focus on integrating advanced analytics of e-commerce data and act as a decision support mechanism for opening new market niche.

The Waterfall, Agile and RAD life cycle models have also been reviewed with each having their own strengths and limitations. Therefore, there is not one best approach that can fit for all situations. Instead, considerations must be given to constraints that are unique to specific projects. For developing a B40 online business platform, factors that influence the selection of life cycle model includes client engagement, a small but experienced team of developers, requirement of prototype in the initial phase of the project, large-scale system deployment, as well as the overall duration of the project. Based on these considerations, RAD model is deemed the most suitable for development of the online business platform. However, since the project involves the B40 segment as stakeholders, the study has proposed a modified version of the RAD life cycle model. 


\section{Acknowledgements}

The study is funded by Universiti Teknologi MARA and the Ministry of Higher Education, Malaysia, through the Long-Term Research Grant Scheme (600-RMC/LRGS 5/3 (001/2020).

\section{References}

[1]. Nair, S., \& Sagaran, S. (2017). Poverty in Malaysia: Need for a paradigm shift. Institutions and Economies, 95-123.

[2]. Binti Abdul Rashid, S. M. R., Hassan, F., \& Samat, N. (2021). The Role of ICT in Breaking a Vicious Cycle of Poverty. Journal of Contemporary Issues in Business and Government, 27(1), 1496-1514.

[3]. Abdull Hamid, N., Haron, N. H., Nik Abdullah, N. A. I., Mohd Ali, M., Abd Hamid, N., \& Abdul Razak, N. (2020). The acceptance of the eRezeki digital platform in Kuala Selangor, Malaysia. International Journal of Innovation, Creativity and Change, 13(3), 609-621.

[4]. Ismail, M. K., Kumaran, V. V., Munawwarah, S. N., Muhamad, M. Z., \& Sarifuddin, S. (2021). COVID19 Outbreak: An Analysis of Malaysian Household Income Class During Movement Control Order (MCO). Studies of Applied Economics, 39(4).

[5]. Akpan, I. J., Udoh, E. A. P., \& Adebisi, B. (2020). Small business awareness and adoption of state-ofthe-art technologies in emerging and developing markets, and lessons from the COVID-19 pandemic. Journal of Small Business \& Entrepreneurship, 1-18.

[6]. Tran, L. T. T. (2021). Managing the effectiveness of e-commerce platforms in a pandemic. Journal of Retailing and Consumer Services, 58, 102287.

[7]. MD AZMI, F. A., Zainudin, A. Z., Jaafar, M. N., Wan Ismail, W. I. F., \& Amdan, M. A. (2021). Towards Stabilizing the Economic Impact of COVID-19 through Fiscal Policy in Malaysia. Geopolitics Quarterly,17(Special Issue), 90-107.

[8]. Ministry of Finance. (2020). Building the economy together: Short-term economic recovery plan JuneDecember 2020. Government of Malaysia.

[9]. Hoa, D. T. P., \& Chen, L. (2020). Policy Environment for E-commerce Connectivity in Viet Nam. E-commerce Connectivity in ASEAN, 120.

[10].Hosseini, F., Sadighi, H., Mortazavi, S. A., \& Farhadian, H. (2019). An E-Commerce SWOT Analysis for Export of Agricultural Commodities in Iran. Journal of Agricultural Science and Technology, 21(7), 1641-1656.

[11].Apau, R., \& Koranteng, F. N. (2019). Impact of Cybercrime and Trust on the Use of E-Commerce Technologies: An Application of the Theory of Planned Behavior. International Journal of Cyber Criminology, 13(2), 228-254.
[12].Hong, J. Y., \& Han, H. N. (2020). Reconfiguring production and logistics networks under the global ecommerce environment, in Chen, L. \& Kimura, F. (Eds.), E-Commerce Connectivity in ASEAN (pp. 216-232). Economic Research Institute for ASEAN and East Asia.

[13]. Ismail, N. A., \& Masud, M. M. (2020). Prospects and Challenges in Improving E-commerce Connectivity in Malaysia. E-commerce Connectivity in ASEAN, 78.

[14].Almarabeh, T., \& Majdalawi, Y. K. (2019). Cloud Computing of E-commerce. Modern Applied Science, 13(1), 27-35.

[15].Ikumoro, A. O., \& Jawad, M. S. (2019). Intention to use intelligent conversational agents in e-commerce among Malaysian SMEs: an integrated conceptual framework based on tri-theories including unified theory of acceptance, use of technology (UTAUT), and TOE. International Journal of Academic Research in Business and Social Sciences, 9(11), 205-235.

[16]. Mangla, S. K., Lenka, S. K., \& Singh, R. (2020). Enabling India's E-commerce Connectivity with ASEAN: E-payment in India-Problems and Prospects. E-commerce Connectivity in ASEAN, 146.

[17].Qiu, Z., \& Yang, Y. (2019). Analysis of rural ecommerce evaluation in Heilongjiang province based on entropy weight method, in Wang, Y. M. \& Zhou, D. C. (Eds.), Proceedings of 2019 5th International Conference on Education, Management and Information Technology (pp. 148-153). Francis Academic Press.

[18].Schach, S. R. (2007). Object-oriented and classical software engineering (Vol. 6). New York: McGrawHill.

[19].Kramer, M. (2018). Best practices in systems development lifecycle: An analyses based on the waterfall model. Review of Business \& Finance Studies, 9(1), 77-84.

[20].Dima, A. M., \& Maassen, M. A. (2018). From Waterfall to Agile software: Development models in the IT sector, 2006 to 2018. Impacts on company management. Journal of International Studies, 11(2), 315-326.

[21].Ambler, S. W. (2003). Agile model driven development is good enough. IEEE Software, 20(5), 71-73.

[22].Beynon-Davies, P., Carne, C., Mackay, H., \& Tudhope, D. (1999). Rapid application development (RAD): an empirical review. European Journal of Information Systems, 8(3), 211-223.

[23]. Mackay, H., Carne, C., Beynon-Davies, P., \& Tudhope, D. (2000). Reconfiguring the user: Using rapid application development. Social studies of science, 30(5), 737-757.

[24].Hu, L. (2019). E-commerce Trade Consumption Payment Security and Privacy Based on Improved B2C Model. Int. J. Netw. Secur., 21(4), 545-550. 
[25].Lubis, A., Lumbanraja, P, \& Hasibuan B. (2019). eCommerce readiness to support SMEs in tourism area: Case of North Sumatera, in Abhari, K., Arsad, N., Ikhsan, R. B., Senanuch, P., \& Nasution, M. I. (Eds.), Proceedings of 1st International Conference on Economics, Management, Accounting and Business. Universitas Muhammadiyah Sumatera Utara.

[26]. Shahzad, A., Hassan, R., Abdullah, N. I., Hussain, A., \& Fareed, M. (2020). COVID-19 impact on ecommerce usage: An empirical evidence from Malaysian healthcare industry. Humanities \& Social Sciences Reviews, 8(3), 599-609.

[27].Cirqueira, D., Hofer, M., Nedbal, D., Helfert, M., \& Bezbradica, M. (2019). Customer Purchase Behavior Prediction in E-commerce: Current Tasks, Applications and Methodologies. In International Workshop New Frontiers in Mining Complex Patterns.

[28]. Shakya, S. (2019). An efficient security framework for data migration in a cloud computing environment. Journal of Artificial Intelligence, 1(01), 45-53.

[29].Rane, M., Patra, S., Khan, U., \& Gutte, Y. (2019). Medkwick - An e-commerce mobile application based on online medicine shopping. International Research Journal of Engineering and Technology, 6(4), 1875-1879.
[30].Al Harizi, S., \& Al Marhoon, S. O. (2019). Factors Affecting the Adoption of E-Commerce: An Evidence from Developing Country. Int. J. Sci. Manag. Stud, 2(3), 86-90.

[31].Kamanghad, A., Hashemzadeh Khorasgani, G., Afshar Kazemi, M., \& Shadnoosh, N. (2019). Assessing the Company's E-Readiness for implementing Mobile-CRM System: Case A Nationwide Distribution Company. Journal of Information Systems And Telecommunication (JIST),[online], 7(1), 65-73.

[32]. Sarker, I. H., Faruque, F., Hossen, U., \& Rahman, A. (2015). A survey of software development process models in software engineering. International Journal of Software Engineering and Its Applications, 9(11), 55-70.

[33].Amlani, R. D. (2012). Advantages and limitations of different SDLC models. International Journal of Computer Applications \& Information Technology, 1(3), 6-11.

[34].Petersen, K., \& Wohlin, C. (2009). A comparison of issues and advantages in agile and incremental development between state of the art and an industrial case. Journal of systems and software, 82(9), 14791490. 